Resenba 


\title{
Literatura de viagem de Wilhelm Ludwig von Eschwege
}

\author{
Günther H. Augustin I UFMG
}

\begin{abstract}
candidato mais recente para ingressar, com os relatos de suas viagens, no cânone da literatura de viagem sobre o Brasil, é Wilhelm Ludwig von Eschwege, chamado em Minas de o "Senhor Barão". Filho de uma família da nobreza decadente alemã, resolveu viajar e procurar sua sorte no mundo afora, porque seu amor por sua namorada Sofia não podia ser respondido. Os pais dela não o acharam digno da posição social da família da amada. Foi contratado pela coroa portuguesa para dar assistência ao então Superintendente de Minas em Portugal, José Bonifácio de Andrada e Silva, com o qual manteve uma longa amizade. Veio com Dom João VI para, o então, Brasil colonial preindependente e acompanhou de perto o que, conforme a classificação de Florestan Fernandes, teria sido a primeira fase da revolução da burguesia brasileira (1808-22). Dessa revolução, Eschwege percebeu pouco. Pelo contrário; falou dos mineiros conservadores e desconfiados e, numa das raras observações políticas, reclamou da morosidade do ministério em atender suas propostas de modernização, e se atreve a dizer que precisaria de uma revolução para mudar isso.

Foi mandado a Minas Gerais para fazer um levantamento das riquezas mineralógicas, controlar o contrabando de ouro e pacificar os botocudos. Da última tarefa desistiu, por achar que os portugueses haviam destruído qualquer possibilidade de convivência pacífica com os índios, pois a tentativa de
\end{abstract}


transformá-los implicaria em sua destruição. Para solucionar a segunda tarefa propôs, entre outras coisas, a construção de uma muralha chinesa. Da primeira, resultou seu relato Pluto Brasiliensis, traduzido e publicado no Brasil como volumes 58 e 59 da Coleção Reconquista do Brasil em 1979. Na capa do segundo volume consta que

Poucos homens terão feito por Minas e pelo Brasil, em toda a sua vida, mais que o Barão de Eschwege ... chamado o "Pai da Geologia Brasileira", como poderá verificar a leitura desta obra, bem como, a seguir, a do volume de seu Diário do Brasil, também incluído na "Coleção". Entretanto, forçoso é lamentar que, fora das áreas eruditas da Geologia e da Mineralogia, é nome pouco conhecido do grande público.

Na primeira folha daquele volume encontra-se a lista dos volumes da Coleção da época, com alguns deles marcados como "No Prelo", entre estes o volume 48, que deveria ter sido publicado como Diário do Brasil. Mas esse não saiu, e Eschwege continuou pouco conhecido, até que, em 2002, depois de um longo processo de tradução, esse relato foi apresentado ao grande público sob o título Jornal do Brasil, numa bela edição da Fundação João Pinheiro, Centro de Estudos Históricos, em Belo Horizonte, na série "Coleção MINEIRIANA". Na mesma coleção foram publicados Brasil, novo mundo em 1996 (vol. I) e 2001 (vol. II). Assim, os livros de Eschwege saíram no Brasil em ordem inversa em relação às publicações na Alemanha, onde o primeiro dos três relatos, o Journal von Brasilien, foi publicado em dois volumes, em Weimar, em 1818, ou seja, enquanto Eschwege ainda se encontrava no Brasil. O segundo, Brasilien, die Neue Welt, escrito, em dois volumes, logo após o seu retorno à Alemanha em 1822, foi editado ou reimpresso três vezes, em 1824, 1827 e 1830, atestando o seu sucesso editorial e a reputação do viajante como principal "brasilianista" da época na sua pátria. Finalmente, de volta a Portugal, Eschwege escreve o Pluto brasiliensis, publicado em 1833, em Berlim.

Esta demora da publicação de versões brasileiras dos relatos de Eschwege fez com que aparecessem em um contexto diferente daquele de 25 anos atrás, quando a reconquista do Brasil foi concebida pela publicação e leitura de relatos, na maioria de estrangeiros, de representantes dos colonizadores.

1. ESCHWEGE, 1979a, contracapa. 
Hoje procura-se reavaliar o imaginário brasileiro reconquistando um sistema intelectual mais independente de modelos europeus ou norte-americanos. Isso pode levar a uma leitura mais crítica dos livros dos viajantes e suas idéias enquanto "fora do lugar".

O contexto também mudou nos Estudos Literários. Houve uma abertura para tipos de textos tradicionalmente não considerados dignos de análise literária. Os relatos dos viajantes representam um novo gênero, a literatura de viagem, que trabalha com um conceito de literatura mais aberto, já que distinções entre fato e ficção ou prosa e poesia estão perdendo nitidez. O olhar do viajante e o do poeta se encontram nesses textos. Utilizando uma conceituação da época dos nossos viajantes, diríamos que o viajante textualiza seu olhar externo dos fenômenos enquanto o poeta, o interno. Dentro dessas perspectivas os textos de Eschwege convidam para leituras e análises que vão além da procura de informações históricas, sociológicas, econômicas, etnológicas ou antropológicas e visam o que Bento Prado Jr. chama, na falta de melhor expressão, um conhecimento literário do mundo.

Do ponto de vista da produção ou criação dos textos de Eschwege, podemos até um certo ponto acompanhar o nascimento da escrita do viajante. Manifesta-se em Eschwege o que podemos chamar um Schreibtrieb compensatório, um impulso de escrever para afirmar-se como homem e cientista, mas também em função do mecanismo epistemológico da época que exigia a busca do conhecimento e a sua fixação. Essa gênese confere certa autenticidade à escrita do viajante. Há evidências que Eschwege sofria de complexo de inferioridade como cientista e escritor. Logo no início do Pluto Brasiliensis, depara com a dificuldade em separar textualmente acontecimentos relacionados intimamente uns com os outros já que, na narrativa, a simultaneidade tem que ser seqüencializada. "Só uma pena hábil, melhor portanto que a minha, poderia tornar interessante a dissecação histórica de matéria tão curiosa quanto instrutiva. Na falta de outros recursos, limitar-me-ei à descrição dos fatos." ${ }^{2}$ Na introdução ao Brasil, novo mundo o autor mostra mais confiança. Fala dos seus trabalhos literários e promete um fio condutor nas suas descrições. Só que esse fio não aparece.

No início do Jornal do Brasil Eschwege descreve o primeiro dia de uma viagem, saindo de Vila Rica (Ouro Preto) em direção à cidade de Mariana. O texto demonstra de modo exemplar como a "descrição dos fatos" acaba

2. ESCHWEGE, 1979, p. 23. 
criando um texto denso, rico e significativo. O viajante, com seu olhar de múltiplas perspectivas, anota na sua jornada uma diversidade de impressões cuja representação textualizada lhe confere sentidos ou não, conforme o(s) modelo(s) de realidade do autor. Ele anota tanto a riqueza quanto a pobreza, a decadência, a perda de recursos, a falta de conhecimentos e de coragem, a exploração da natureza e dos homens, as formações naturais e sociais e, em poucos momentos, as belezas naturais e urbanas. Sua percepção intuitiva transforma-se em texto discursivo utilizando tropos como antropomorfização, metonímia, metáforas, ironia, paradoxo, paralelismos, polissemia, analogia e símbolos, criando uma rede de significações que representam uma visão particular das evidências empíricas. A descrição aparentemente desinteressada deixa transparecer comentários, interpretações, interrogações, questionamentos e críticas, naturalizando o negro na sua posição e função social e sugerindo que o ouro é preto porque foi extraído pelo trabalho dos negros.

Enquanto nos primeiros textos, ainda tímido e sem pretensões. costura-se uma rede significativa pela pura textualização do visto, mais tarde Eschwege escreve com a autoridade do autor que usa de forma consciente e na dosagem certa expedientes como metáfora, paradoxo e ironia para criar um texto simples, mas profundo, que expressa o sentido metafórico do "ouro preto" quando interfere no debate sobre a abolição da escravidão e resume sua experiência:

Até agora o escravo, [sic] tem sido pau para toda obra: lavrador, fabricante de açúcar e de aguardente, animal de transporte, máquina de britagem e de pulverização, cozinheiro, pajem, palafreneiro, sapateiro, alfaiate, correio e carregador. É o único bem do homem livre, a cujas necessidades ele provê. Sem seu auxílio, o branco poderia considerar-se pobre, mesmo que suas arcas regurgitassem de ouro. Com efeito, as terras permaneceriam incultas e a mineração desapareceria, caso não existisse o escravo que fizesse todos esses serviços. É ele quem cuida da própria alimentação do senhor, que, se assim não fosse, teria de viver miseravelmente, ou de emigrar para outras terras, onde seu ouro tivesse alguma serventia. ${ }^{3}$

Não são muito freqüentes os trechos com uma visão mais literária do mundo, num universo de 1.348 páginas entre diários, relatos, cartas, descrições

3. ESCHWEGE, 1979a, p. 263. 
inclusive de outros autores, listas e tabelas. Indicamos três: uma descrição na tradição humboldtiana, uma reflexão sentimental e uma transcendental.

Enquanto no primeiro relato do Jornal do Brasil podemos perceber a riqueza textual apesar da falta de um programa de escrita, a não ser a necessidade ou obrigação de produzir um relato caminhando, olhando e anotando, o primeiro texto de Brasil, novo mundo intitulado no original Fluechtig skizzirtes Naturgemaelde des Hafens von Rio de Janeiro (Quadro de natureza esboçado do porto do Rio de Janeiro $)^{4}$ é um texto bem diferente, bem elaborado. Evidenciamse como intertextos a Estética transcendental, de Kant, e Ansichten der Natur (Vistas da Natureza), de Alexander von Humboldt. Deste último consta no título do texto o conceito básico da sua proposta de um estilo estético-científico da literatura de viagem, o Naturgemälde (Quadro de natureza), e no decorrer do texto aparecem as palavras Ansichten der Natur no seu sentido primário, mas ecoando o título programático de Humboldt. Com referências a Kant e Humboldt, o autor alinha seus discursos àqueles destes autores; ao mesmo tempo se diferencia deles, dando a entender que não é Dichter (poeta) e nem Denker (pensador), no sentido filosófico.

Uma das raras vezes em que a narrativa de Eschwege se transforma em poesia, articulando a alma e as emoções no peito do viajante com suas saudades e desejos, é quando descreve sua profunda solidão durante uma das suas viagens. "O dia transcorreu de forma tão monótona que nada surgiu que mereça um comentário." Por falta de assunto descreve o acampamento: "O rancho tinha paredes até a metade e estava limpo." Nos textos do viajante, o rancho é o símbolo da falta de um lar; é quase sempre semi-aberto e nele nunca podese sentir em casa. Olhando em volta, comenta: "Mas a mais graciosa das paisagens não satisfaz quando não se vê nela sinal de atividade humana." E logo em seguida admite: "Nunca me senti tão só e abandonado como quando pernoitava ou errava pelos campos sem fim, em geral tão belos, dos sertões de Minas. ... Eu teria morrido de tristeza se não me acorresse à mente a lembrança de minha Pátria, ..." Depois de salvo pela recordação, todos os sentimentos de saudade, amor e amizade acordaram e os desejos se articulam: "desejos brotaram de desejos."

Apesar de todo esforço textual, toda tropologia, o texto registra a inexpressibilidade do sentimento da solidão, reconhecendo que a língua é um

4. ESCHWEGE, 1827, p. 1 e ESCHWEGE, 1996, p. 57.

5. ESCHWEGE, 2001. p. 69-70. 
instrumento limitado e às vezes inadequado para representar os fenômenos. Às vezes a palavra de outra língua é mais adequada, como no caso de "saudade" no texto alemão, à qual o viajante recorre para finalizar: "Para o conjunto desses sentimentos que me esforcei por descrever ao leitor, tem o português a palavra saudade, que não se pode traduzir por nenhuma outra nos idiomas que conheço."

No final do Brasil, novo mundo 2, portanto no final dos seus relatos de viagens sobre o Brasil, Eschwege inclui "Algumas notícias sobre as nações indígenas do sul do Brasil". Sob o pretexto de descrever diferenças dos índios no sul e nas províncias do norte do Brasil, o texto articula uma reflexão sobre origem, civilização, cultura e um ser superior, textualizada através da oposição simbólica entre "luz clara do sol", associada ao céu e aos campos abertos e a escuridão das "montanhas sombrias e matas impenetráveis." Contudo, o olhar transcende os fenômenos e abre-se para a memória, a magia, a fantasia e a alma, alma do viajante e dos homens da mata. Nesse olhar transcendental o narrador viaja pela história do homem, refletindo sobre "uma origem mais elevada", pretensões a uma "cultura mais elevada" e "sentimentos de um ser superior", compondo um discurso crítico da civilização. Na medida em que os olhares fenomenal e transcendental se misturam, o texto generaliza suas reflexões e não visa apenas as nações indígenas do sul ou do norte do Brasil, mas todos os homens de mentalidade sombria ou clara.

Muito diferentes são os habitantes dos campos, cujo olhar acostumou-se com um horizonte mais aberto e sobre o qual o céu claro atua como benéfica magia, uma magia que produz seus resultados, cobre de verde os campos e lhe desperta no peito o sentimento de um ser superior. Em vez de viverem apenas da caça e seguirem com mãos sujas de sangue e mentalidade sanguinária as trilhas fugidias da caça, acabam por se tornar tranqüilos povos pastores e, como antes, o sangue, passa a ser o leite o alimento dos povos.

6. ESCHWEGE, 2001. p. 70.

7. ESCHWEGE, 2001. p. 151-152.

8. ESCHWEGE, 2001. p. 152 


\section{Referências Bibliográficas}

ESCHWEGE, W. L. v. Jornal do Brasil, 1811-1817. Trad. Friedrich E. Renger, Tarcísia L. Ribeiro e Günter Augustin. Belo Horizonte: Fundação João Pinheiro, Centro de Estudos Históricos e Culturais, 2002.

ESCHWEGE, W. L. v. Brasil, novo mundo. Vol. II. Trad. Myriam Ávila. Belo Horizonte: Fundação João Pinheiro, Centro de Estudos Históricos e Culturais, 2001.

ESCHWEGE, W. L. v. Brasil, novo mundo. Trad. Domício de Figueiredo Murta. Belo Horizonte: Centro de Estudos Históricos e Culturais. Fundação João Pinheiro, 1996.

ESCHWEGE, W. L. v. Pluto Brasiliensis. Vol. 1. Trad. Domício de Figueiredo Murta. Belo Horizonte: Ed. Itatiaia; São Paulo: Ed. da Universidade de São Paulo, 1979.

ESCHWEGE, W. L. v. Pluto Brasiliensis. Vol. 2. Trad. Domício de Figueiredo Murta. Belo Horizonte: Ed. Itatiaia; São Paulo: Ed. da Universidade de São Paulo, 1979a.

ESCHWEGE, L. W. v. Pluto Brasiliensis. Berlin: G. Reimer, 1833.

ESCHWEGE, L. W. v. Brasilien die Neue Welt. Erster Theil. Braunschweig: Friedrich Vieweg, 1827.

ESCHWEGE, L. W. v. Brasilien die Neue Welt. Zweiter Theil. Braunschweig: Friedrich Vieweg, 1824.

ESCHWEGE, W. C. v. Journal von Brasilien. Erster Heft. Weimar: Handels- und Industrie Verlag, 1818.

ESCHWEGE, W. C. v. Journal von Brasilien. Zweiter Heft. Weimar: Handels- und Industrie Verlag, 1818. 